Jounal of
Epidemiology and Community Health, 1979, 33, 100-103

\title{
A comparison of two proxy measures for morbidity
}

\author{
R. J. GANDY \\ From the Leicestershire Area Health Authority (Teaching)
}

SUMMARY The use of standardised mortality ratios (SMRs) as a proxy measure of morbidity for resource allocation purposes in the National Health Service (NHS) has been widely criticised. The small number of deaths from infectious diseases makes it necessary to consider whether there are more appropriate measures. The standardised notification rate (SNR) was compared with the SMR for respiratory tuberculosis and it appears to be a better proxy for morbidity.

The Resource Allocation Working Party (Department of Health and Social Security, 1976) recommended fundamental changes in the formula for the distribution of revenue to the Regional Health Authorities (RHAs). One of the major components in the new formula was mortality as measured by the SMR. To assess relative need for health care, the SMRs for each RHA would be used as a proxy for morbidity in weighting the population. For nonpsychiatric hospital inpatients, the SMR would be used for separate diagnostic groups. For nonpsychiatric day and outpatients, community health services, and ambulance services, the 'all causes' SMR would be used. The working party established that 'all causes' SMRs, when applied to inpatients, gave broadly the same results as condition-specific SMRs. The working party recommended that the principles used in allocation to RHAs should be applied to allocations below regional level.

This use of the SMR has been widely questioned. A report by the World Health Organisation considered that where the numbers of deaths per year in the age range of one week to 55 years are small, mortality rates are unlikely to reflect the need for medical care (World Health Organisation, 1972). Forster (1977) found that there was no significant correlation between standardised mortality rates and acute sickness, bed sickness, or sickness causing work or school absence as measured by the General Household Survey. A Barr and R. F. Logan (1977) expressed concern at the assumption made by the working party of the existence of a direct linear relationship between mortality and morbidity. This would imply that every proportional increase in mortality carries the same proportional increase in morbidity - a supposition for which there is little supportive hard evidence.

The standardised notification rate (SNR) is an alternative to the SMR for infectious diseases. The question is whether it is a better proxy for morbidity.
Because some infectious diseases have a very low mortality rate, it was decided to concentrate the study on an infectious disease which was a major cause of death compared with other infectious diseases. The disease chosen was respiratory tuberculosis (including late effects).

In its 1968 study, the British Thoracic and Tuberculosis Association (BTTA) (1971) considered the accuracy of tuberculosis mortality data in England and Wales. It stated that of all deaths in England and Wales attributed to tuberculosis of all types each year, $25 \%$ were not notified as cases of tuberculosis before death. However, the study found that of 844 tuberculosis deaths investigated, 334 $(46 \%)$ were such that tuberculosis could be considered to be irrelevant to the cause of death.

The completeness of the notification of respiratory tuberculosis has been estimated to be about $90 \%$ (Benjamin, 1968). It is probable that this estimate included geographical variations, since in 1972 the number of notifications per 100 deaths from respiratory tuberculosis ranged from 426 in the South-western Regional Hospital Board to 1166 in the North-west Metropolitan Regional Hospital Board.

\section{COMPARISONS BETWEEN THE SMR}

AND THE SNR

Information concerning SMRs and SNRs by sex was obtained for the 14 former English Regional Hospital Boards (RHBs) and the Welsh Hospital Board for 1968 and 1973. The RHBs were ranked for each statistic and compared, using the method of rank correlation described by Kendall (1970). The values of Kendall's rank correlation coefficient are summarised in Table 1.

It can be seen that whereas the SMR and SNR had significant correlations at the $5 \%$ level in 1968 , there was little correlation in 1973. Part of the reason for this was the smaller number of deaths in 1973 from 
Table 1 Comparisons of SMR and SNR

\begin{tabular}{llll}
\hline & $\begin{array}{l}\text { Kendall's rank } \\
\text { correlation } \\
\text { coefficient }\end{array}$ & $\begin{array}{l}\text { Standard } \\
\text { errors }\end{array}$ & $\begin{array}{l}\text { Probabilities } \\
\text { (approx.) }\end{array}$ \\
\hline Statistics compared & 0.45 & 0.28 & 0.03 \\
$\begin{array}{c}\text { SMR (males) 1968 } \\
\text { SNR (males) 1968 }\end{array}$ & 0.45 & 1.58 & 0.15 \\
$\begin{array}{c}\text { SMR (males) 1973 } \\
\text { SNR (males) 1973 }\end{array}$ & 0.31 & 1.98 & 0.05 \\
$\begin{array}{c}\text { SMR (females) 1968 } \\
\text { SNR(females) 1968 }\end{array}$ & 0.39 & 0.94 & 0.38 \\
$\begin{array}{c}\text { SMR (females) 1973 } \\
\text { SNR (females) 1973 }\end{array}$ & 0.19 & & \\
\hline
\end{tabular}

Table 2 Comparisons of SMR and SNR over time

\begin{tabular}{llll}
\hline & $\begin{array}{l}\text { Kendall's rank } \\
\text { correlation } \\
\text { coefficient }\end{array}$ & $\begin{array}{l}\text { Standard } \\
\text { errors }\end{array}$ & $\begin{array}{l}\text { Probabilities } \\
\text { (approx.) }\end{array}$ \\
\hline Statistics compared & 2.18 & 0.03 \\
$\begin{array}{c}\text { SMR (males) 1968 } \\
\text { SMR (males) 1973 }\end{array}$ & 0.43 & 4.26 & $<0.001$ \\
$\begin{array}{c}\text { SNR (males) 1968 } \\
\text { SNR (males) 1973 }\end{array}$ & 0.83 & 2.13 & 0.03 \\
$\begin{array}{c}\text { SMR (females) 1968 } \\
\text { SMR (females) 1973 }\end{array}$ & 0.42 & 3.66 & $<0.001$ \\
$\begin{array}{c}\text { SNR (females) 1968 } \\
\text { SNR (females) 1973 }\end{array}$ & 0.71 & & \\
\hline
\end{tabular}

respiratory tuberculosis. (1968 deaths: 1382 males, 476 females; 1973 deaths: 872 males, 311 females).

To discover whether either index fluctuated over time, the SMR and SNR rankings for both sexes for 1968 were compared with those for 1973 . Kendall's rank correlation method was again applied. The results are summarised in Table 2 .

In order to calculate how sensitive the two indices were to random fluctuations, it was considered appropriate to examine one RHA and one area within that region. The convenient choices were Trent RHA and Leicestershire, because of the availability of local data. In 1975, Trent RHA had 657 notifications of respiratory tuberculosis (432 males and 225 females). One more male notification would have caused an increase in the SNR (males) of $0.23 \%$. One more female notification would have caused an increase in the SNR (females) of $0.44 \%$. The number of deaths from respiratory tuberculosis in Trent RHA in 1975 was 105 (77 males and 28 females). The increase in the SMR caused by one more death would have been $1.30 \%$ for males and $3 \cdot 57 \%$ for females.

The indices are subject to wider fluctuations on an area basis. The total number of notifications in Leicestershire in 1975 was 203 (118 males and 85 females). One more male notification would have caused an increase in the SNR (males) of $0.85 \%$; the SNR (females) would have increased by $1 \cdot 18 \%$ on one more female notification. The total number of deaths in Leicestershire from respiratory tuberculosis in 1975 was 15 . With such small numbers, it was considered more appropriate to consider the period 1974-1976 and combine the figures. Table 3 gives details of the numbers of deaths and shows the percentage increase should one more death have occurred, either male or female.

Table 3 Respiratory tuberculosis deaths in Leicestershire, 1974-76

\begin{tabular}{lrlll}
\hline & 1974 & \multicolumn{1}{l}{1975} & 1976 & \multicolumn{1}{l}{ Average } \\
\hline Male & $7(14 \cdot 3 \%)$ & $11(9 \cdot 1 \%)$ & $8(12 \cdot 5 \%)$ & $8 \cdot 67(11.5 \%)$ \\
Female & $10(10.0 \%)$ & $4(25.0 \%)$ & $6(16.7 \%)$ & $6 \cdot 67(15.0 \%)$ \\
\hline
\end{tabular}

Figures in brackets show the percentage increase that would result if one more death occurred.

The number of male deaths in hospital in Leicestershire from respiratory tuberculosis during this period was $20(77 \%)$ and of female deaths 16 (80\%).

MORTALITY AND NOTIFICATION IN A

SUB-GROUP OF THE POPULATION

In 1965 and 1971, the BTTA $(1966 ; 1973)$ conducted national surveys on the effect of immigration on tuberculosis notifications in England and Wales. When the results of the two surveys were compared, it was found that although there had been a decline in the number of notifications of tuberculosis among lifelong residents of the British Isles, there had been an appreciable increase in notifications for persons born in India, Pakistan, and the new Commonwealth countries in Africa (BTTA, 1975). It was also shown that the most recent arrivals in England and Wales among these immigrants had higher rates of tuberculosis than those who had lived here longer.

It was appropriate, therefore, to consider the effects on the SMR and SNR of such a sub-group of the population. Leicestershire has a large Asian community and so have Bradford and Birmingham. Information on the ethnic origin of cases of respiratory tuberculosis in Leicestershire in 1975 was kindly provided from a local survey.

Similar information for deaths in 1974-76 was obtained from the registers of the local chest clinics. The clinics are notified of tuberculosis deaths whenever possible. In order to maintain accuracy, the registers are checked quantitatively with the details on form SD25 published by the Office of Population Censuses and Surveys every year.

Table 4 gives details of notifications in Leicestershire in 1975 for each age, sex, and ethnic group. Table 5 gives similar information for deaths in Leicestershire in the period 1974-1976.

The relative risk between the two ethnic groups shows that an Asian male is $\mathbf{5 6 . 4}$ times more likely 
Table 4 Notifications of respiratory tuberculosis in Leicestershire, 1975

\begin{tabular}{|c|c|c|c|c|c|c|c|c|c|c|c|c|}
\hline \multirow[b]{2}{*}{$\begin{array}{l}\text { Age group } \\
\text { (years) }\end{array}$} & \multirow[b]{2}{*}{$\begin{array}{l}\text { Male } \\
\text { No. }\end{array}$} & \multicolumn{3}{|c|}{$A S I A N$} & \multicolumn{4}{|c|}{ NON-ASIAN } & \multirow[b]{2}{*}{$\begin{array}{l}\text { Male } \\
\text { No. }\end{array}$} & \multicolumn{2}{|c|}{ TOTAL } & \multirow[b]{2}{*}{ Rate } \\
\hline & & Rate & $\begin{array}{l}\text { Female } \\
\text { No. }\end{array}$ & Rate & $\begin{array}{l}\text { Male } \\
\text { No. }\end{array}$ & Rate & $\begin{array}{l}\text { Female } \\
\text { No. }\end{array}$ & Rate & & Rate & $\begin{array}{l}\text { Female } \\
\text { No. }\end{array}$ & \\
\hline $\begin{array}{c}0-4 \\
5-14 \\
15-24 \\
25-34 \\
35-44 \\
45-64 \\
65+\end{array}$ & $\begin{array}{r}1 \\
2 \\
30 \\
22 \\
14 \\
19 \\
2\end{array}$ & $\begin{array}{r}41 \cdot 7 \\
40 \cdot 7 \\
726 \cdot 9 \\
563 \cdot 7 \\
457 \cdot 2 \\
743 \cdot 9 \\
333 \cdot 3\end{array}$ & $\begin{array}{r}1 \\
8 \\
21 \\
12 \\
13 \\
9 \\
3\end{array}$ & $\begin{array}{r}42 \cdot 6 \\
177 \cdot 0 \\
534 \cdot 4 \\
388 \cdot 6 \\
577 \cdot 0 \\
513 \cdot 7 \\
704 \cdot 2\end{array}$ & $\begin{array}{l}0 \\
0 \\
7 \\
1 \\
4 \\
8 \\
8\end{array}$ & $\begin{array}{l}\overline{ } \\
\overline{11} \cdot 8 \\
2.0 \\
8.7 \\
9.0 \\
20.8\end{array}$ & $\begin{array}{l}0 \\
0 \\
4 \\
3 \\
4 \\
5 \\
2\end{array}$ & $\begin{array}{l}- \\
\overline{7} \cdot 1 \\
6 \cdot 3 \\
8 \cdot 9 \\
5 \cdot 4 \\
3 \cdot 3\end{array}$ & $\begin{array}{r}1 \\
2 \\
37 \\
23 \\
18 \\
27 \\
10\end{array}$ & $\begin{array}{r}2 \cdot 9 \\
3 \cdot 0 \\
58 \cdot 1 \\
42 \cdot 8 \\
36 \cdot 6 \\
29 \cdot 6 \\
25 \cdot 6\end{array}$ & $\begin{array}{r}1 \\
8 \\
25 \\
15 \\
17 \\
14 \\
5\end{array}$ & $\begin{array}{r}3 \cdot 0 \\
12 \cdot 5 \\
41 \cdot 6 \\
29 \cdot 7 \\
36 \cdot 1 \\
15 \cdot 0 \\
8 \cdot 3\end{array}$ \\
\hline Total & 90 & $417 \cdot 5$ & 67 & $365 \cdot 8$ & 28 & $7 \cdot 4$ & 18 & $4 \cdot 6$ & 118 & $27 \cdot 0$ & 85 & $20 \cdot 8$ \\
\hline
\end{tabular}

Rates calculated per 100000 population.

Table 5 Deaths from respiratory tuberculosis in Leicestershire, 1974-76

\begin{tabular}{|c|c|c|c|c|c|c|c|c|c|c|c|c|}
\hline \multirow[b]{2}{*}{$\begin{array}{l}\text { Age group } \\
\text { (years) }\end{array}$} & \multirow[b]{2}{*}{$\begin{array}{l}\text { Male } \\
\text { No. }\end{array}$} & \multirow{2}{*}{$A S I A N$} & \multirow{2}{*}{\multicolumn{2}{|c|}{$\begin{array}{l}\text { Female } \\
\text { No. Rate }\end{array}$}} & \multirow[b]{2}{*}{$\begin{array}{l}\text { Male } \\
\text { No. }\end{array}$} & \multicolumn{3}{|c|}{ NON-ASIAN } & \multirow[b]{2}{*}{$\begin{array}{l}\text { Male } \\
\text { No. }\end{array}$} & \multicolumn{2}{|c|}{ TOTAL } & \multirow[b]{2}{*}{ Rate } \\
\hline & & & & & & Rate & $\begin{array}{l}\text { Female } \\
\text { No. }\end{array}$ & Rate & & & $\begin{array}{l}\text { Female } \\
\text { No. }\end{array}$ & \\
\hline $\begin{array}{l}<45 \\
45-64 \\
65+\end{array}$ & $\begin{array}{l}1 \\
2 \\
2\end{array}$ & $\begin{array}{r}18 \cdot 1 \\
261 \cdot 0 \\
1111 \cdot 1\end{array}$ & $\begin{array}{l}1 \\
2 \\
1\end{array}$ & $\begin{array}{r}18 \cdot 2 \\
3805 \\
782 \cdot 5\end{array}$ & $\begin{array}{r}0 \\
9 \\
12\end{array}$ & $\begin{array}{r}-33 \cdot 8 \\
104 \cdot 1\end{array}$ & $\begin{array}{l}\mathbf{0} \\
9 \\
7\end{array}$ & $\begin{array}{l}\overline{32} \cdot 7 \\
38 \cdot 8\end{array}$ & $\begin{array}{r}1 \\
11 \\
14\end{array}$ & $\begin{array}{r}1 \cdot 2 \\
40 \cdot 2 \\
119 \cdot 6\end{array}$ & $\begin{array}{r}1 \\
11 \\
8\end{array}$ & $\begin{array}{r}1 \cdot 3 \\
39 \cdot 2 \\
44 \cdot 0\end{array}$ \\
\hline Total & 5 & $77 \cdot 3$ & 4 & $72 \cdot 8$ & 21 & $18 \cdot 5$ & 16 & $13 \cdot 7$ & 26 & $21 \cdot 7$ & 20 & $16 \cdot 3$ \\
\hline
\end{tabular}

Rates are calculated per million population on the average number of deaths for one year during the period.

to have respiratory tuberculosis notified than a nonAsian male. For females the figure is $79 \cdot 5$. However, this figure did vary between age groups. A major reason for the total difference was the differing population structures of the two communities. The Asian community was younger than the indigenous population: $35.6 \%$ were under the age of 16 and $2 \cdot 6 \%$ over 65 , compared with $24 \cdot 1 \%$ and $12 \cdot 8 \%$ respectively for the non-Asians.

The relative risk of dying from the disease presented a different picture. Asians were again more at risk than non- Asians. However, the relative risk was only $4 \cdot 2$ for males and $5 \cdot 3$ for females.

The effect of the two communities on the SMR and SNR can be gauged by considering the actual numbers of deaths and nocifications. Approximately $80 \%$ of deaths were non-Asian for both males and females. However, for notifications, $76 \%$ of males were Asian and $79 \%$ of females were Asian. It can, therefore, be deduced that the SNR is affected by the middle-aged Asian population while the SMR is affected by the elderly part of the indigenous population. This may change at some time in the future when the Asian community acquires a similar population structure to that of the rest of the population.

\section{DEMANDS MADE ON RESOURCES}

For resource allocation it is necessary to consider which of the two measures better reflects the demands on resources. In order to do this the RHBs were ranked according to the number of deaths and discharges per 100000 population for both males and females in 1972. This information was obtained from the Hospital In-Patient Enquiry. The rankings were then compared with the SMR and SNR using Kendall's method of rank correlation (Kendall, 1970). The results are shown in Table 6.

Table 6 Comparison of SMR and SNR with discharge rates for Regional Hospital Boards in 1972

\begin{tabular}{llll}
\hline $\begin{array}{l}\text { Statistics compared } \\
\text { (1972) }\end{array}$ & $\begin{array}{l}\text { Kendall's rank } \\
\text { correlation } \\
\text { coefficient }\end{array}$ & $\begin{array}{l}\text { Standard } \\
\text { errors }\end{array}$ & $\begin{array}{l}\text { Probabilities } \\
\text { (approx.) }\end{array}$ \\
\hline $\begin{array}{l}\text { SMR (males) Discharge } \\
\text { rate (males) }\end{array}$ & 0.73 & 3.76 & 0.001 \\
$\begin{array}{l}\text { SNR (males) Discharge } \\
\text { rate (males) }\end{array}$ & 0.37 & 1.88 & 0.060 \\
$\begin{array}{l}\text { SMR (females) Discharge } \\
\text { rate (females) }\end{array}$ & 0.12 & 0.59 & 0.550 \\
$\begin{array}{l}\text { SNR (females) Discharge } \\
\text { rate (females) }\end{array}$ & 0.49 & 2.48 & 0.015 \\
\hline
\end{tabular}

The correlation between SNR (males) and the discharge rate (males) was not significant at $5 \%$. However, it was still high. The SMR for females was still a large problem showing minimal correlation. The limitation of the comparisons was that a lot of care for respiratory tuberculosis is provided in outpatient clinics. Typically, a general practitioner who suspects that a patient has the disease refers him or her to an outpatient clinic where tests will be undertaken. If these are positive, the patient will probably follow a course of outpatient treatment and a notification of the disease will be made. When the patient is very ill, a hospital admission will be made. In addition, for positive cases a health visitor visits the patient's home and makes arrangements for the family and other contacts to attend an outpatient clinic for investigation. Much will depend on the patient's circumstances. 
It can be seen that for each notification, large demands can be made on NHS resources. In Leicestershire in 1975 there were 13.6 notifications for every male death from respiratory tuberculosis. The figure for females was $12 \cdot 8$.

\section{Discussion}

It is generally agreed that resource allocation should make allowance for morbidity. Unfortunately, the term 'morbidity' is not specific and it is therefore immeasurable as a single entity. The RAWP argues that the SMR is a good proxy measure for morbidity. However, the SMR for an infectious disease such as respiratory tuberculosis lacks consistency because of the small number of deaths involved, and the SNR would appear to be a more appropriate measure. The SMR is affected mostly by the elderly indigenous population, whereas the SNR in the area of the detailed study is affected by the Asian population. The limitation on the SNR is that in spite of the large numbers involved, notifications can indicate, at best, only the incidence of an infectious disease. No information is readily available on the prevalence of an infectious disease or on the use made of resources. The choice of index therefore depends upon what is being considered.

In 1975 , respiratory tuberculosis was reponsible for $37 \%$ of all deaths from infectious diseases, but only $4 \%$ of all notifications. This implies that the SMR would be less appropriate for other infectious diseases than it is for respiratory tuberculosis. However, it is debatable whether the SNR should be used for all infectious diseases, because many are treated in the home and consequently make little or no demand on NHS resources. Therefore, for each infectious disease, it is necessary to consider whether to use the SNR as a proxy measure for morbidity or to use no proxy measure at all for resource allocation.

It is unlikely that a universal proxy measure can be found for morbidity that satisfies all the requirements of resource allocation. Consequently, research is necessary to determine the most appropriate proxy measure for each set of diagnoses. For example, the National Cancer Registration and
Disabled Persons Registers may yield improved measures for their respective conditions.

\section{Conclusion}

The SNR, by measuring relative incidence, is a more appropriate proxy measure for morbidity than the SMR for respiratory tuberculosis (including late effects). This is probably also true for other infectious diseases. The SNR is particularly sensitive to the demands placed on the NHS resources by the high risk Asian population for respiratory tuberculosis. Therefore, for purposes of resource allocation and those infectious diseases that make demands on NHS resources, the SNR is a more appropriate proxy measure of morbidity than the SMR.

I thank Dr. M. Clarke and Mr. D. Clayton of the Department of Community Health, Leicester University, Mr. N. Samani, Mrs. Baxter, and Mr. Smith.

Reprints from R. J. Gandy, Leicestershire Area Health Authority (Teaching), Hearts of Oak House, 9, Princess Road, Leicester LE1 6TG

\section{References}

Barr, A., and Logan, R. F. (1977). Policy alternatives for resource allocation. Lancet, 1, 994-997.

Benjamin, B. (1968). Health and Vital Statistics, p. 171. George Allen and Unwin.

British Thoracic and Tuberculosis Association (1971). Tubercle, 52, 1.

British Thoracic and Tuberculosis Association (1973). Tubercle, 54, 249.

British Thoracic and Tuberculosis Association (1975). British Medical Journal, 3, 698-699.

British Tuberculosis Association (1966). Tubercle, 47, 145. Department of Health and Social Security (1976). Sharing Resources for Health in England. Report of the Resource Allocation Working Party. HMSO: London.

Forster, D. P. (1977). Mortality, morbidity, and resource allocation. Lancet, 1, 997-998.

Kendall, M. G. (1970). Rank Correlation Methods, fourth edition. Griffin: London.

World Health Organisation (1972). Technical Report Series No. 472. WHO: Geneva. 